\title{
Sulfur-Stabilized Carbanions: Electrophilic Reactions of an Allylic Anion Containing Propanedithio and Phenylthio Substituents
}

\author{
Jim-Min Fang * Ming-Yi Chen \\ Department of Chemistry, National Taiwan University, Taipei, 10764, Taiwan, Republic of China \\ Received 22 February 1990
}

Abstract: In contrast to the $\gamma$-regioselective reactions of $1,1,3$ tris(phenylthio)propene, the anion of 2-(2-phenylthioethylidene)1,3-dithiane reacts with halides and aldehydes preferentially at the propanedithio-substituted carbon ( $\alpha$-regioselective reaction), but at the phenylthio-substituted carbon with open-chain aliphatic ketones. This umpolung reagent is utilized to prepare $\alpha, \beta$-unsaturated ketones and oxygen-containing heterocyclic compounds.

$\alpha$-Hetero-substituted carbanions have been widely employed in the carbon-carbon bond formation. The sulfur-stabilized carbanions are especially useful synthons because they are easily accessible and the reaction products can be further elaborated to other functional compounds. For example, 1,3-bis(methylthio)propene and 1,3bis(phenylthio)propene has been used as umpolung reagent via a sequence of deprotonation, alkylation and hydrolysis to give $\alpha, \beta-$ unsaturated aldehydes. 1 Although an unsymmetric allylic anion may have two reactive sites, the anion of allyl phenyl sulfide (1 or 2) reacts with alkyl halides selectively at the phenylthio-substituted carbon (the $\alpha$-site). ${ }^{2}$ However, the regiochemistry for the electrophilic reaction of sulfur-stabilized allylic anions can be affected by several factors ${ }^{3}$ including the substituents of the allylic anion, the attacking electrophile, the counter cation, the solvent, the Lewis acid, and the reaction temperature. We and others have studied a series of 2-vinyl-1,3. dithianes to find that the regioselectivity for these ambident anions is greatly influenced by $r$-substituents, 4 such as the cyano, the methyl, the phenyl, and the o-methoxyphenyl groups. The present study of the electrophilic reactions of an analog 3 having the $\gamma$-substituent of phenylthio group is designed to test the power of the propanedithiosubstituent verse the phenylthio-substituent in control of the regiochemistry. It is also interesting to compare the reactivity of 3 with that of 1,1,3-tris(phenylthio)propene (4). 5

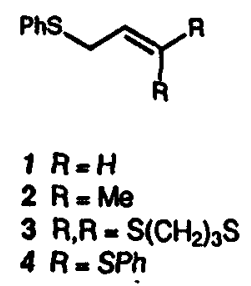

The substrate 2-(2-phenylthio-ethylidene)-1,3-dithiane 3 was prepared according to Scheme 1 by (i) consecutive treatment of $\alpha$-bromoncrolein with thiophenol (1 equiv) and 1,3-propanedithiol (1 equiv) in the presence of borontrifluoride and (ii) subsequent dehydrobromination with 1,8-diazabicyclo[5.4.0]undec-7-ene. Deprotonation of 3 with $n$ Buli in THF gave an unsymmetric allylic anion, which underwent electrophilic reactions at $-78^{\circ} \mathrm{C}$ with alkyl halides, aldehydes and ketones as shown in Table 1.6 Unlike the exclusive $\gamma$-regioselective reactions of 1,1,3-tris(phenylthio)propene, 5 the preliminary result for 3 indicated variable selectivities depending on the respective attacking electrophile. The reaction with methyl iodide or benzyl bromide occurred predominantly at he propanedithio-substituted carbon to give the $\alpha$-substitution product $5 \mathrm{a}$ or $6 \mathrm{a}$. Over $80 \%$ of $\alpha$-addition was also observed with the electrophiles of most aldehydes and benzophenone. On the contrary, the addition of open-chain aliphatic ketones favored at the phenylthio-substituted carbon. The reason for such non-unified regiochemical outcome is not obvious. Neither the steric effect nor the electronic effect, e.g. the HSAB principle, 4,5 can be satisfactorily applied to explain the difference in regiochemistry.

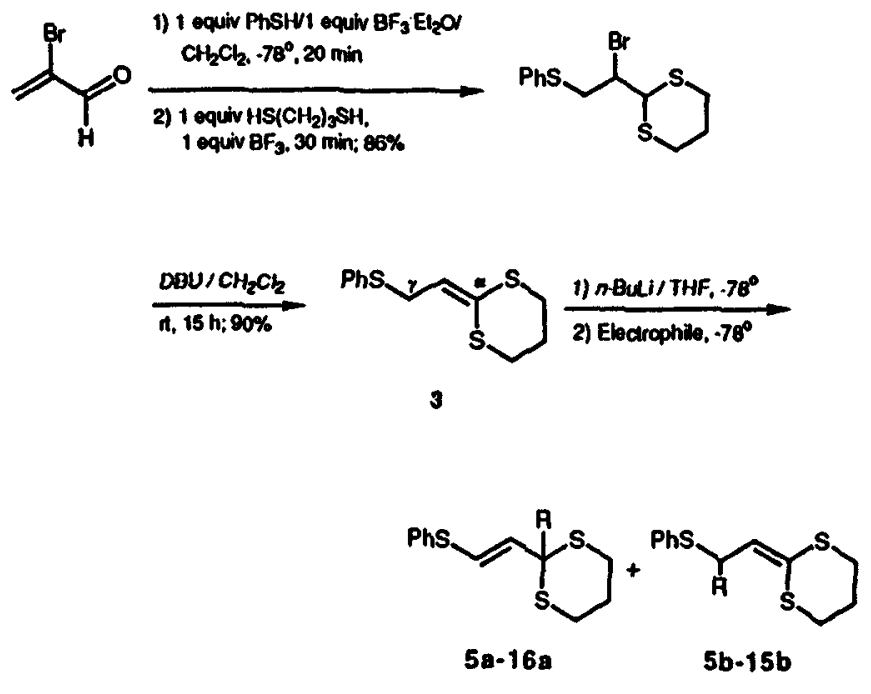

Scheme 1

Table I. Electrophilic Reactions of the Anion of 3 .

\begin{tabular}{lll}
\hline Electrophile & $\mathrm{R}=$ & product (yield, \%) \\
\hline iodomethane & $\mathrm{Me}$ & $5 \mathrm{a}(52)^{\mathrm{a}}+5 \mathrm{~b}(30)$ \\
benzyl bromide & $\mathrm{CH}_{2} \mathrm{Ph}$ & $6 \mathrm{a}(63)+6 \mathrm{~b}(27)$ \\
propanal & $\mathrm{CH}(\mathrm{OH}) \mathrm{CH}_{2} \mathrm{Me}$ & $7 \mathrm{a}(86)$ \\
isobutanal & $\mathrm{Cll}(\mathrm{OH}) \mathrm{CHMe}$ & $8 \mathrm{a}(62)+8 \mathrm{~b}(16)^{\mathrm{b}}$ \\
acrolein & $\mathrm{CH}(\mathrm{OH}) \mathrm{CH}=\mathrm{CH}_{2}$ & $9 \mathrm{a}(58)$ \\
benzaldehyde & $\mathrm{CH}(\mathrm{OH}) \mathrm{Ph}$ & $10 \mathrm{a}(68)$ \\
cinnamaldehyde & $\mathrm{CH}(\mathrm{OH}) \mathrm{CH}=\mathrm{CHPh}$ & $11 \mathrm{a}(23)+11 \mathrm{~b}(47)^{\mathrm{b}}$ \\
2-butanone & $\mathrm{MeC}(\mathrm{OH}) \mathrm{Cl}{ }_{2} \mathrm{Me}$ & $12 \mathrm{a}(20)+12 \mathrm{~b}(65)^{\mathrm{b}}$ \\
3-pentanone & $\mathrm{MeCH} 2 \mathrm{C}(\mathrm{OH}) \mathrm{CH} \mathrm{He}_{2}$ & $13 \mathrm{~b}(87)$ \\
2-heptanone & $\mathrm{Me}(\mathrm{CH})_{4} \mathrm{C}(\mathrm{OH}) \mathrm{Me}$ & $14 \mathrm{~b}(90)^{\mathrm{b}}$ \\
cyclopentanone & $(\mathrm{CH})_{4} \mathrm{C}(\mathrm{OH})$ & $15 \mathrm{a}(41)+15 \mathrm{~b}(41)$ \\
benzophenone & $\mathrm{PhC}(\mathrm{OH}) \mathrm{Ph}$ & $16 \mathrm{a}(83)$ \\
\hline
\end{tabular}

(a) All $\alpha$-addition products ( 5 a-16a) have the $E$-double bonds as inferred from large coupling constants ( $\mathrm{ca} .16 \mathrm{~Hz}$ ) of the vinyl protons. (b) The $\gamma$-addition product $12 \mathrm{~b}$ or $14 \mathrm{~b}$ consists of two diastercomers in nearly equal amounts, whereas $8 \mathrm{~b}$ or $11 \mathrm{~b}$ is homogeneous presumably to have the threoconfiguration. 
The present method serves an entry to syntheses of $\alpha, \beta-$ unsaturated ketones and oxygen-containing heterocyclic compounds (Eq 1-4). For instance, hydrolysis of the $\alpha$-addition product $16 \mathrm{a}$, obtained from the reaction with benzophenone, with $\mathrm{HgCl}_{2}$ yielded an $\alpha^{-}$-hydroxy- $\alpha, \beta$ unsaturated ketone 17. The $\alpha$-addition product $8 \mathrm{a}$ cyclized in similar conditions to give a tetrahydrofuran 18 without hydrolysis of the dithioacetal, while 10 a ended up with a furan 19 by further elimination of $\mathrm{PhSH}$ and opening of the dithiane ring. The raddition products $\mathbf{8 b}$, $12 \mathrm{~b}$ and $14 \mathrm{~b}$ were successfully transformed into the butenolides 20 22.

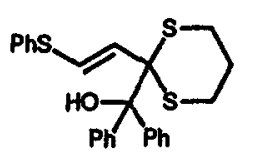

$16 a$<smiles>CC(C)C(O)C1(/C=C/c2ccccc2)SCCCS1</smiles>

1) $\mathrm{HgCl} / \mathrm{CH}_{3} \mathrm{CN} / \mathrm{H}_{2} \mathrm{O}$ 2) $\mathrm{NaBH}_{4} / \mathrm{NaOH}: 62 \%$

(Eq2)

$8 a$<smiles>OC(c1ccccc1)C1(/C=C/[PbH2])CSc2ccccc21</smiles>
1) $\mathrm{HgCl}_{2} / \mathrm{CH}_{3} \mathrm{CN} / \mathrm{H}_{2} \mathrm{O}$ $\frac{60^{\circ}, 3 \mathrm{~h}}{\text { 2) } \mathrm{NaBH}_{4} / \mathrm{NaOH}_{5} 57 \%}$

(Eq3)

$10 \mathrm{a}$<smiles>[R]C([2H])(O)C(C=C1SCCCS1)C(=S)c1ccccc1</smiles><smiles>[R]C1(P)C=CC(=O)O1</smiles>

(Eq 4)<smiles>SCCCSc1ccoc1-c1ccccc1</smiles>

19

$\begin{array}{cccc}8 b & R=\mathrm{CHMO}_{2} & \mathrm{~F}=\mathrm{H} & 20 \\ 12 b & \mathrm{CH}_{2} \mathrm{Me}^{\prime} & \mathrm{Me} & 21 \\ 14 b & \left(\mathrm{CH}_{2}\right)_{4} \mathrm{Me} & \mathrm{Me} & 22\end{array}$

Acknowledgment. We thank the National Science Council (R.O.C) for financial support.

\section{References and Notes}

(1) Corey, E. J.; Erickson, B. W.; Noyori, R. J. Am. Chem. Soc. 1971, 93, 1724.

Cohen, T.; Bennett, D. A.; Mura, A. J. J. Am. Chem. Soc. 1976, 41, 2506.

(2) Biellmann, J. F.; Ducep, J. B. Tetrahedron Lett. 1968, 5629.

(3) Oshima, K.; Yamamoto, H.; Nozaki, H. Bull. Chem. Soc. Jpn. 1975, 48, 1567.

Wada, M.; Nakamura, H.; Taguchi, T.; Takei, H. Chem. Lett. 1977, 345.

Binns, M. R.; Haynes, R. K. J. Org. Chem. 1981, 46, 3790. Biellmann, J. F.; Ducep, J. B. Org. React. 1982, $27,1$. Wiley: New York.

(4) Meyers, A. I.; Strickland, R. C. J. Org. Chem. 1972, 37, 2579.

Seebach, D.; Kolb, -M. Liebigs, Ann. Chem. 1977, 811. Ziegler, F. E.; Tam, C. C. J. Org. Chem, 1979, 44, 3428. Ziegler, F. E.; Fang, J. M.; Tam, C. C. J. Am. Chem. Soc. 1982, 104, 7174.

Murphy, W. S.; Wattanasin, S. J. Chem. Soc. Perkin Trans. 1, 1980, 2678.

Kozikowski, A. P.; Chen, Y. Y. J. Org. Chem. 1980, 45, 2236.

Fang, J. M.; Hong, B. C.; Liao, L. F. J. Org. Chem. 1987, $52,855$.

Fang, J. M.; Chen, M. Y.; Yang, W. J. 1988, 29, 5937.

M. Y. Chen; Fang, J. M. J. Chin. Chem. Soc. (Taipei) 1989, $36,469$.

(5) Dziadulewicz, E.; Gallagher, T. Tetrahedron Lett. 1985, 26 , 4547.

(6) Compounds 3 and 5-22 are fully characterized by spectral methods (IR, MS and NMR) and by elemental analyses or exact mass measurements. 